\title{
First European MeEting of the OCEANOGRAPHY SOCIETY
}

\author{
Amsterdam, the Netherlands \\ July 8-11, 1996
}

\author{
Melbourne G. Briscoe, TOS Secretary
}

W

hen The OCEanography Society began, in 1988, it was a founding principle to have high-quality scientific meetings that encouraged interdisciplinary discussions, leisurely exchange of ideas, and a chance to reflect on fundamental aspects of the ocean sciences and their interactions. Today, as life gets more hurried and science gets more harried, it seems more important than ever to give ocean scientists and practitioners a chance to look back, look ahead, and look around.

That early decision by TOS was not taken lightly, and it has been an expensive decision to support. The economics of professional societies are fragile: fiscal stability comes from large membership. many publications, and most importantly very well attended meetings. Oceanography is not a large field, there are already many publications, and large meetings tend to be synonymous with many simultaneous sessions and many short talks. The TOS founders looked enviously at the economics of large meetings with many papers being presented, but decided instead to try a new style of meeting: morning plenary sessions with just a few, high-quality, long (30-60 minute) talks on topics of broad interest, with afternoons of open poster sessions to maximize "parallel processing." lively discussion, and cross-fertilization of ideas and topics.

The first TOS biennial scientific meeting. in Monterey in 1989, proved the concept. There was a definite market for the new "TOS-style" meeting. The sec- ond and third meetings, in St. Petersburg (1991) and Seattle (1993), showed that the concept was valid, but not always easy to implement. High-quality talks. accompanied by high-quality graphics, were something that required considerable advance planning and a real commitment by the speakers. Meanwhile, the experience of the community in preparing poster presentations, and the technology to do so, began to grow to maturity. It was no longer a cutting-edge effort to produce large graphics, color, even interactive exhibits. In 1994 TOS tried the first of its "even year" meetings in Honolulu, billed as Pacific Basin Meeting with emphasis on TOGA. It had a slightly modified style (a few parallel oral sessions); although the idea of a narrow scientific focus worked out fine, some attendees who had been fans of the three earlier biennial meetings were perturbed at a possible shift toward the "AGU meeting" format. The biennial meeting in Newport in 1995 returned strongly to the "pure" TOS format of morning plenaries, afternoon posters.

It was an important decision by the TOS council in 1994, after the Honolulu meeting. to hold the next available TOS meeting in Europe, i.e. in 1996 after Newport in 1995. TOS was founded as an international society, but water runs downhill: about $80 \%$ of the membership were from the U.S., and all the meetings had so far been held in the U.S. Honolulu was an attempt to entrain some Asian oceanographers into one of our meetings, but what about Europe? The strategy was to plan the European meeting in cooperation with European oceanographers, and with the cooperation of European-based societies and the International Council of Scientific Unions (ICSU).

\section{Amsterdam Meeting Report}

TOS held its first meeting with an European venue in Amsterdam, 8-11 July, 1996. The site was chosen to be centrally located, easy to get to, and attractive to North American oceanographers (the largest membership group in TOS). The meeting theme was the Role of the Ocean in Global Change, highlighting the oceanographic aspects and importance of the Human Dimensions of Global Change Programme (HDP), the International Geosphere-Biosphere Programme (IGBP), and the World Climate Research Programme (WCRP). Although each of these programs has had many scientific meetings, this was the first attempt to bring together the many disciplines to share progress and issues. These three large programs and the Scientific Committee on Oceanic Research (SCOR) worked with TOS to make the meeting happen.

James McCarthy (Harvard University) and Raymond Pollard (Southampton Oceanography Centre) were the program co-chairs; session conveners were Richard Barber (Duke University) for the Tropical Oceans, Robert Dickson (Ministry of Agriculture, Fisheries, and Food, UK) for the Mid-Latitudes, Peter Killworth (Southamptom Oceanography Centre) for the Role of the Polar Oceans in 
Climate, and Vere Shannon (University of Cape Town) and Patrick Holligan (Southampton Oceanography Centre) for Shelf Systems and Environmental Change: Implications for Resources. Climate, and Society. The local organizing chair was Annalies Pierrot-Bults from the University of Amsterdam. Financial support was provided by the Foundation for the Advancement of Oceanographic Research in the Netherlands. the Mayor and Aldermen of Amsterdam, the Netherlands Oceanographic Club. the Research School of Sedimentary Geology (NL), the Royal Netherlands Academy of Arts and Sciences, the Zoological Museum of the University of Amsterdam, and the (US) Office of Naval Research and its ONR Europe office in London. UK. ONR, which is celebrating its 50th birthday in 1996, held a birthday party and symposium during the meeting, including a boat trip through the canals to a reception and poster exhibition at the Amsterdam Maritime Museum. A report on the ONR symposium, with pictures, may be found on the World Wide Web at URL http://www.ehis.navy.mil:80/cdnews5.htm.

Approximately 230 people registered for the meeting, representing some 25 countries in Europe. North America. Asia, Africa. and Oceania. About 10 percent of the registrants were students. Of the 18 invited papers, 14 were solely or jointly by non-North American authors; of the 119 posters presented. 77 were solely or jointly by non-North American authors. It was clearly an international meeting.

In addition to the scientific goal of exposing and strengthening the interfaces between the global change programs and on larger-scale geographic variability from the tropics to the poles - a goal that was strongly met-a secondary goal of the meeting was to expose the TOS meeting format to the European oceanographic community and gain adherents to TOS and to the TOS concept of thoughtful, interdisciplinary presentation and discussion. In this latter goal, some quotes from one of the session chairs, a European:

"I'd never experienced this style before but . . . it worked."

"[there is] a reputation that in the TOS sessions you are going to see something new, not necessarily always some newlybreaking story, but maybe a new slant to something old. And given by the best people. There I think we met our task admirably."

"A structure that added more than the sum of its parts."

"The TOS format does offer something rare and worthwhile."
As one meeting-goer said on the airplane going back home after the meeting:

"It was a small, but very high-quality meeting. I met some really interesting people and actually had time to talk to them. I saw some old friends. I learned some new things. I got some new ideas. And I am taking home some excellent cheese. What more could you ask for? It was a very good meeting."

\section{Epilogue}

The TOS Council is pleased with the first European meeting of the Society, and has agreed to hold its 1998 scientific meeting again in Europe. European and national professional societies have been contacted as to their interest in cosponsorship. and we anticipate an announcement soon as to the time and place. Our great desire is to strengthen the view of TOS as an international society speaking for interdisciplinary oceanography in all its forms, in all its locations. We wish not to compete with national organizations but rather to act as an aid in seeing them all work together; our view of the ocean is that it is global; our view of oceanography and its institutions is that they too must have a global perspective, even of local science and problems. 


\section{The Oceanography’s Society’s 1997 Scientific Meeting "OCEAN INTERFACES"}

\section{Seattle, Washington, USA \\ April 1-4, 1997}

THE OCEANOGRAPHY SOCIETY (TOS), announces its 1997 scientific meeting, to be held in Seattle. WA, April 1-4, at the Seattle Sheraton Hotel (plenary sessions) and the Washington State Convention \& Trade Center (posters and exhibits).

The meeting format will include morning plenary sessions of invited talks on the daily session themes and contributed poster abstracts in the afternoons focusing on, but not limited to, the day's session theme (no poster session on the last day). Commercial exhibits will be co-located with the contributed posters. Registration fee will include a daily continental breakfast, morning and after- noon coffee breaks, and one reception (possibly more). Students are invited to attend and participate. 100 students will be permitted to register at half the regular registration fee. The half-price registrations will be allocated on a first-come basis, but preference will be given to students submitting abstracts and presenting posters.

Some financial support will be available from SCOR for oceanographers from developing countries; applications for this support must be received at TOS headquarters by January 31, 1997.

\section{CALL FOR POSTER ABSTRACTIONS}

\section{Abstract \& Poster Information}

Poster abstracts will be accepted for review December 1, 1996-February 21, 1997. Abstract titles and content need not be specific to one of the broad session themes as outlined in the Preliminary Program included here.

Abstracts relating to the session theme of a given day will be presented on that day. Abstracts not specific to the session themes will be presented on the day assigned them by the Abstract Manager. Every attempt will be made to assign posters for presentation on the day preferred by the author but, to balance the number of posters over the course of the meeting, TOS reserves the right to make the final assignments.

All submitted abstracts will be reviewed by the Program Chair. Abstract acceptance notices will be issued no later than March 7. Every effort will be made to issue early notifications of poster acceptance to those who submit abstracts in advance of the deadline.

\section{Abstract Format}

Abstracts are limited to 300 words, including title and author(s) information (name[s], affiliation[s], and address[es]. An Internet address for the first author is requested. Overly long abstracts will be returned to the author for editing.

\footnotetext{
Abstract Fees

The abstract fee is US\$70 (US\$35 for students). Payment of the abstract fee must be made at the time the abstract is submitted and can be made with check or money order, payable to "The Oceanography Society" (in U.S. funds payable on a U. S. bank) or with a credit card (Master Card or Visa only). Abstracts submitted via e-mail or FAX must be paid with a credit card for which the account number and expiration date are provided when the abstract is sent. We regret that we are unable to process training or purchase orders and cannot issue invoices for payment. Fees for abstracts that are not accepted will be refunded. Revisions to abstracts are discouraged; revised abstracts will be treated as new submissions and will be charged an additional US\$70 (US\$35).
}

\section{Abstract Submissions}

Electronic mail is the preferred method for submitting abstracts and will ensure the quickest acceptance notification. Abstracts may also be submitted to TOS via FAX. mail. or other delivery service.

E-mail and FAX: Submit abstracts via e-mail as text files (no "attachments"). Abstracts submitted in this manner must include credit card information as below.

Mail or Delivery Service: Submit in duplicate to TOS headquarters with a check. money order or credit card information as below.

With all submissions, please indicate the following information:

- credit card account number (Mastercard or VISA only), expiration date and name that appears on the card (if applicable);

- name, address, e-mail address, phone number, and fax number of the person to receive the acceptance notification;

- preferred day of presentation if the abstract is unrelated to one of the daily session themes;

- any special poster requirements (see "Furnishings and Services for Posters" below).

The Oceanography Society

4052 Timber Ridge Drive,

Virginia Beach. VA 23455, USA

E-mail: jrhodes@ccpo.odu.edu

FAX: (757) 464-1759; Phone: (757) 464-0131

\section{Furnishings and Services for Posters}

TOS will provide the $4^{\prime} \times 8^{\prime}$ poster frame with a display area of $46^{\prime \prime}$ (vertical) $\times 91^{\prime \prime}$ (horizontal) on which to mount posters. If your poster requires electricity (approximately \$50/outlet) and/or additional furnishings (such as a table or computer cart) there will be an additional charge. Such special requirements must be indicated when your abstract is submitted. You will be billed for those additional items and payment must be received in advance of the meeting to ensure availability. On-site orders for additional services/furnishings (if available) will be at a substantially higher price and charges for them must be paid in full upon delivery. 


\section{GENERAL INFORMATION}

\section{Registration}

All participants, including poster presenters, must register for the meeting. A brochure containing registration information, forms and final program will be available in November 1996.

\section{Hotel ACCOMmodations}

The Sheraton Seattle Hotel and Towers will serve as the headquarters hotel. Special meeting rates are $\$ 110$ single $\$ 131$ double. Reservations can be made by calling the Sheraton Seattle's Reservations Department at (206) 447-5555. Be sure to mention that you will be attending The Oceanography Society meeting. The deadline for these special rates is February 28, 1997 after which reservations will be taken on a space and rate available basis.

\section{INFORMATION UPDATES}

TOS members and those who have requested being placed on the meeting mailing list will be sent an updated printed brochure when it is available. If you wish to be placed on the mailing list or if you are on the list but have not received the brochure by December 15, 1997, please contact TOS headquarters. Meeting updates will also appear at the TOS website (http://www.tos.org).

\section{PRELIMINARY PROGRAM}

Meeting Program Chair: Mike Reeve, National Science Foundation (NSF), USA

\section{SCIENCE TheME}

"Interfaces of the Vertical Ocean"

Tuesday, April 1: "The Air-Sea Interface"

Session Chair: Robert Duce, Texas A\&M University, USA

- Ocean-atmosphere exchange and climate modeling

- Iron, biology and climate

- Particle exchange between ocean and atmosphere

- Policy issues related to air-sea exchange

- TECHNOLOGY FOCUS: Innovations in measurements at the air-sea interface

Wednesday. April 2: "The Mixed Layer-Deep Ocean Interface"

Session Chair: Ann Gargett, Institute of Ocean Sciences, Canada

- Connections between physics and biology on a variety of scales

- Differential vertical transports of temperature and salinity and implications for circulation and ecosystem modeling

- New insights into the vertical flux of buoyancy and its ecosystem implications

- TECHNOLOGY FOCUS: Measuring vertical flux of particles to the deep sea

- TECHNOLOGY FOCUS: New ways to observe turbulence in the upper ocean

Thursday. April 3: "The Sea Floor Interface"

Session Chair: John Delaney, University of Washington, USA

- Eruptions and other transient seafloor events

- The hot deep biosphere

- Chemical exchanges between sediments and watercolumn

- Ocean circulation below the seafloor

- TECHNOLOGY FocUs: Designing a seafloor observatory for the 21 st century
Friday, April 4: "Policy, Perspectives, New Directions and Late Breaking News"

Session Chair: Mike Reeve, National Science Foundation, USA

The plenary session on the last morning will explore the interface between public policy and oceanography and reflect on how we got here and where we might be heading into the 21 st century. Posters relating to this session will be welcomed and will be presented with the science and technology posters during the first three days of the meeting.

\section{Technology Theme}

"Interface Between Technology and Oceanography"

Session Chair: Larry Clark, National Science Foundation. USA

This theme will be woven throughout the science plenaries and in focused poster sessions each afternoon. Posters on technology and instrumentation development will be welcomed, including the areas of computing. visualization. satellite and other remote sensing sensors and biotechnology and insights on how new technological developments drive research innovation. If you are interested in organizing clusters of related posters, please contact Larry Clark (hclark@nsf.gov).

\section{Education Speclal Session}

"Interface Between Education (Kindergarten to High School) and Oceanographers"

\section{Session Chair: Patricia Morse}

What are the responsibilities of oceanographers in grade school education, how can you participate effectively, how can you influence curricula? Short presentations will be made on topics such as new paradigms for $\mathrm{K}-12$ science education. new national science standards, the use of technology in school settings, and personal accounts of diverse ongoing projects, followed by an extensive interactive panel and audience question and answer period. 